\title{
BIBLIKE: IMPLANTAÇÃO DO BIBLIVRE EM ESCOLAS ESTADUAIS NA REGIÃO CENTRO SUL DO CEARÁ
}

\author{
LuCAs BezerRa dos Santos ${ }^{1}$ \\ ORCID: 0000-0001-5714-6754 \\ Lucas Fontineles Pereira ${ }^{2}$ \\ ORCID: 0000-0003-2180-9418 \\ Anderson Silva Mota ${ }^{3}$ \\ ORCID: 0000-0003-4979-289X \\ Pedro Luis Saraiva Barbosa ${ }^{4}$ \\ ORCID: 0000-0001-5091-9005
}

Resumo: Na maioria das bibliotecas, sejam estas nas grandes metrópoles ou mesmo nas pequenas cidades do interior, os antigos controles manuais internos tendem a acabar cada vez mais, por conta do constante avanço tecnológico. Entretanto, algumas bibliotecas das escolas de ensino básico estaduais do Ceará não conseguiram implantar tal automatização em

1 Atualmente é discente do curso de Bacharelado em Sistemas de Informação do Instituto Federal de Educação, Ciência e Tecnologia do Ceará (IFCE) - campus Cedro e bolsista do Programa Institucional de Apoio a Projetos de Extensão (PAPEX) do IFCE. E-mail: (lucassantoscrfbezerra@gmail.com).

2 Atualmente é discente do curso de Bacharelado em Sistemas de Informação do Instituto Federal de Educação, Ciência e Tecnologia do Ceará (IFCE) - campus Cedro e bolsista do Programa Institucional de Apoio a Projetos de Extensão (PAPEX) do IFCE. E-mail: (lucas fontineleslucas@gmail.com).

3 Atualmente é discente do curso de Bacharelado em Sistemas de Informação do Instituto Federal de Educação, Ciência e Tecnologia do Ceará (IFCE) - campus Cedro e bolsista do Programa Institucional de Apoio a Projetos de Extensão (PAPEX) do IFCE. E-mail: (andersonsilv.mota@gmail.com).

4 Possui Mestrado em Engenharia de Software, atualmente é Professor do curso de Bacharelado em Sistemas de Informação do Instituto Federal de Educação, Ciência e Tecnologia do Ceará - campus Cedro e orientador do projeto BibLike contemplado com bolsas do Programa Institucional de Apoio a Projetos de Extensão (PAPEX) do IFCE. E-mail: (pedro.barbosa@ifce.edu.br). 
suas bibliotecas, tendo como um principal fator de não implantação o custo financeiro dessa sistematização que na maioria dos caso é bem alto, tendo assim como consequência perda de livros, mal gerenciamento, demora para confeccionar relatórios, desperdício de tempo com buscas manuais, dificuldades de catalogação, além de não permitir uma maior interação entre aluno, professor e o responsável pela biblioteca. Uma alternativa bastante relevante para solução do problema seria o uso de um software open source. Este trabalho tem por objetivo relatar a experiência de um docente e três bolsistas do Programa de Apoio a Projetos de Extensão (PAPEX) durante a implantação do software open source BibLivre em sua versão 5.0 em três bibliotecas de escolas da rede estadual de ensino do Ceará. A metodologia está dividida em duas fases. A primeira fase é composta de: definição da equipe, firmar parcerias com as escolas, estudar sobre o estado da arte, estudar sobre o BibLivre. A segunda fase é composta por: implantação do BibLivre no servidor, planejar o treinamento dos usuários, realizar o treinamento e implantar o BibLivre nas bibliotecas. O projeto foi submetido no Edital do PAPEX número 001/2019 durante o mês de abril de 2019 e aprovado no mês de junho de 2019. A equipe do projeto é formada por 01 docente e 03 discentes do curso de Bacharelado em Sistemas de Informação do Instituto Federal de Educação, Ciência e Tecnologia do Ceará - campus Cedro. Os discentes foram contemplados com 06 meses de bolsa. As atividades do projeto iniciaram no primeiro dia do mês de agosto de 2019. A implantação do software nas bibliotecas resolveu os problemas internos de gerenciamento destas bibliotecas como: perda de livro, mal gerência e perca de tempo com catalogação manual.

Palavras-chave: BibLivre. Sistema para Bibliotecas. Sistemas de Gerenciamento de Bibliotecas.

\section{BIBLIKE: IMPLEMENTATION OF LIBRARY IN SCHOOLS}

Abstract: In most libraries, whether they are in large cities or even small towns in the interior, the old internal manual controls are tending to end more and more due to constant technological advancement. However, some libraries of the state schools of Ceará failed to implement such automation in their libraries, having as a major factor of non-implementation the financial cost of this systematization which in most cases is very high, resulting in the loss of books. , poor management, slow reporting, wasted time searching, cataloging, and do not allow for greater interaction between student, teacher, and library manager. A very relevant alternative to solve the problem would be the use of open source software. This paper aims to report the experience of one teacher and three fellows of the Extension Project Support Program (PAPEX) during the implementation of open source software BibLivre in its version 5.0 in three schools libraries of the state school system of Ceará. The methodology is divided into two stages. The first stage consists of: team definition, establishing partnerships with schools, studying about the state of the art, studying about BibLivre. The second stage comprises: deploying BibLivre on the server, planning user training, conducting training, and deploying BibLivre in libraries. The project was submitted in PAPEX during April 2019 and approved in June 2019. The project team is made up of 01 teachers and 03 students of the Bachelor of Information Systems course the Institute's Ceará Federal Education, Science and Technology - Cedro campus. The students were awarded 6 months of scholarship. The project activities began on the first day of August 2019. Deploying 
the software in the libraries solved the internal management problems of these libraries such as book loss, mismanagement and waste of time with manual cataloging.

Keywords: BibLivre. System for libraries. Library Management Systems.

\section{BIBLIKE: IMPLEMENTACIÓN DE BIBLIVRE EN ESCUELAS ESTATALES EN LA REGIÓN CENTRAL DEL SUR DE CEARÁ}

Resumen: En la mayoría de las bibliotecas, ya sea en grandes ciudades o incluso en pequeñas ciudades del interior, los viejos controles manuales internos tienden a terminar cada vez más debido al constante avance tecnológico. Sin embargo, algunas bibliotecas de las escuelas estatales de Ceará no implementaron dicha automatización en sus bibliotecas, teniendo como factor principal de no implementación el costo financiero de esta sistematización que en la mayoría de los casos es muy alto, lo que resulta en la pérdida de libros. , gestión deficiente, informes lentos, búsqueda de tiempo desperdiciada, catalogación y no permiten una mayor interacción entre el estudiante, el maestro y el administrador de la biblioteca. Una alternativa muy relevante para resolver el problema sería el uso de software de código abierto. Este documento tiene como objetivo informar la experiencia de un maestro y tres becarios del Programa de Apoyo al Proyecto de Extensión (PAPEX) durante la implementación del software de código abierto BibLivre en su versión 5.0 en las bibliotecas de tres escuelas del sistema escolar estatal de Ceará. La metodología se divide en dos fases. La primera fase consiste en: definición del equipo, establecer asociaciones con las escuelas, estudiar sobre el estado del arte, estudiar sobre BibLivre. La segunda fase comprende: implementar BibLivre en el servidor, planificar la capacitación de los usuarios, llevar a cabo la capacitación e implementar BibLivre en las bibliotecas. El proyecto se presentó en el Aviso público PAPEX número 001/2019 durante abril de 2019 y se aprobó en junio de 2019. El equipo del proyecto consta de 01 maestros y 03 estudiantes del curso de Licenciatura en Sistemas de Información del Instituto Federal Education, Science and Technology do Ceará - campus de Cedro. Los estudiantes recibieron 6 meses de beca. Las actividades del proyecto comenzaron el primer día de agosto de 2019. La implementación del software en las bibliotecas resolvió los problemas de gestión interna de estas bibliotecas, como la pérdida de libros, la mala gestión y la pérdida de tiempo con la catalogación manual.

Palabras claves: BibLivre. Sistema para bibliotecas. Sistemas de gestión de bibliotecas.

Submetido em: 01/0/2019.

Aceito em: 04/10/2019.

\section{INTRODUÇÃO}

Uma grande parte das escolas estaduais do Ceará, têm bibliotecas simples que na maioria dos casos não tem uma infraestrutura completa, que possa dar um suporte eficaz aos estudantes que as utilizam, sendo isto ocasionado por uma série de fatores que corroboram com esta situação. Um desses fatores é 
a falta de um sistema de automatização que permita um bom gerenciamento do acervo, mas em alguns casos é alto o custo financeiro dessa sistematização, se tornando assim inviável para as escolas e tendo assim como consequência perda de livros, mal gerenciamento, demora para confeccionar relatórios, desperdício de tempo com buscas manuais e dificuldades de catalogação.

Além disso, um outro fator que vale a pena ser abordado, mesmo este não sendo a ênfase deste projeto é falta de um profissional bibliotecário nas bibliotecas visto a grande importância, que segundo Corrêa, Oliveira e Bourscheid (2002, p. 115) "O bibliotecário escolar tem como função fornecer a informação de maneira rápida e prática ao estudante", ou seja, tem as imprescindíveis funções do fornecimento de informações de maneira direta e objetiva aos estudantes, responsável pela catalogação de exemplares entre outras funções.

Com vista a se amenizar e ou até mesmo resolver tal problemática foi idealizado o projeto de extensão intitulado BibLike. Que tem como objetivo a implantação de um software open source nas bibliotecas públicas estaduais da região centro sul do Ceará, que se encontram nesta situação problemática.

Figueiredo (1999, p. 11) afirma que a automação "proporciona a chave para que os sistemas de informação se aperfeiçoem, se expandam e se liguem com a finalidade de executar melhor o serviço e torná-lo mais conveniente para o profissional e o usuário". Com base nisso uma alternativa bastante relevante para solução do problema, se falando de automação seria o uso de um software open source, que é um programa como qualquer outro, mas que refere-se a uma alternativa totalmente gratuita, garantida por licenças como a GNU General Public License (GPL) que garantem a reutilização, alteração e redistribuição do mesmo.

Os "Software Livre, ou Free Software, conforme a definição de software livre criada pela Free Software Foundation, é o software que pode ser usado, copiado, estudado, modificado e redistribuído sem restrição" (CAMPOS, 2006, on-line). Nessa perspectiva, pode-se dizer que um software open source, nada mais é que um programa como qualquer outro, mas com algumas diferenças entre eles: ser gratuito, pode ser alterado e modificado para maior adaptação

Os softwares open source são na maioria dos casos de fácil acesso. No entanto, o fato de obter aquele programa não nós permite fazer o que quiser deles, as leis autorais impõem uma gama de restrições, acerca do seu uso, tornando assim necessária prévia autorização do autor ou autores para utilização da obra, tais como cópia e reprodução, é exatamente neste ponto que entra em cena as licenças de software livre, que de acordo com Sabino (2011, p. 01) "são 
contratos através dos quais os detentores dos direitos sobre um programa de computador autorizam usos de seu trabalho (dentro do que for permitido em lei) que, de outra forma, seriam exclusivos dos detentores".

Além do simples uso para o usuário final, as licenças permitem que outros desenvolvedores manipulem o código fonte da aplicação, para que o mesmo se adapte a determinado problema, com necessidades mais específicas. A Figura 01 apresenta um gráfico demonstrando quais as licenças open source mais utilizadas.

MIT License, que foi criada pelo Massachusetts Institute of Technology, entre todas as licenças esta é umas das mais recomendada pela Free Software Foundation, por não possuir múltiplas versões, outra vantagem é a clareza de seus termos, como por exemplo, sub licenciar ou vender cópias do software. Por sua vez, a GNU General Public License 2.0 e 3.0 é a mais recomendada pela Free Software Foundation, pois em termos gerais baseia-se nas quatro liberdades gerais, que são " $1^{\circ}$ - Liberdade de executar o programa; $2^{\circ}$ - Liberdade de estudar o programa; $3^{\circ}$ - Liberdade de redistribuir cópias; $4^{\circ}$ - Liberdade de aperfeiçoar o programa" (GNU, 2019, on-line).

Sendo assim, alguns softwares open source, regulamentados pela GNU se destacam. No tocante a gerenciamento e automação de bibliotecas, podemos destacar o Biblivre que de acordo com Miranda (2016, p. 65): “Trata-se de um software para catalogação e a difusão de acervos de bibliotecas públicas e privadas, de variados portes. Além disso, qualquer pessoa pode compartilhar no sistema seus próprios textos, músicas, imagens e filmes".

FIGURA 1: RANKING DE LICENÇAS MAIS UTILIZADAS.

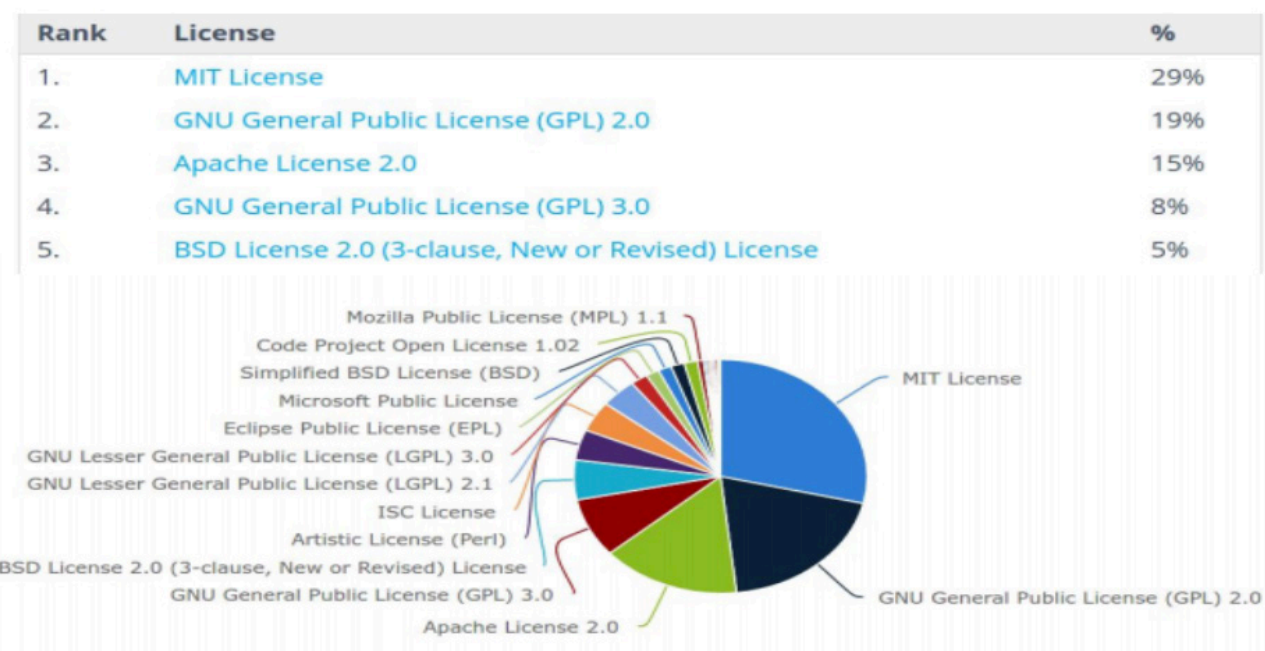

FONTE: MOURÃO (2016). 
O uso de softwares de gerenciamento de bibliotecas que auxiliam a execução de tarefas e promovem celeridade aos processos existentes nesses ambientes têm crescido consideravelmente ao longo das últimas décadas (RACIN, 2014). Ainda é possível se verificar uma certa resistência por parte das pessoas que estão entrando em contato com essas novas ferramentas (MATTOS, 2013). Quer seja por desconhecer as possibilidades de recursos oferecidos, quer seja por ter trabalhado de forma manual (rudimentar) há bastante tempo.

O sistema de ensino-aprendizagem sofre mutações de acordo com a evolução da sociedade. Contudo, nos últimos 20 anos, as mudanças foram bem mais significativas e impactantes. Isso aconteceu devido ao processo conhecido como Revolução Tecnológica. Esse processo continua a transformar os hábitos e comportamentos da sociedade, inclusive as relações de trabalho (SOPHIA, 2018, on-line).

As gerações de alunos (crianças e jovens) que estão em fase escolar já conheceram o mundo com a tecnologia presente no dia a dia e acessível na palma das mãos. Então não seguir esse hábito no processo de ensino-aprendizagem é quase que impossível, afinal a educação precisa ter relação com a vida do estudante, não pode ser algo totalmente paralelo.

Para manipular esses recursos e ferramentas com foco no pedagógico, é necessário que os professores tenham internalizadas algumas habilidades específicas que os possibilitem utilizar todas as funcionalidades dos recursos disponíveis (SOPHIA, 2018, on-line). Dessa forma, é fundamental que o educador esteja pronto para criar relações entre os conteúdos das disciplinas, as diversas aprendizagens da escola e da realidade cotidiana, fazendo desses recursos tecnológicos os seus grandes parceiros para o processo educacional. É justamente nesse ponto que entra em cena os software auxiliares open source, sendo essas ferramentas de grande valia no processo educacional (SOPHIA, 2018, on-line).

Este trabalho tem por objetivo relatar a experiência de um docente e três bolsistas do Programa de Apoio a Projetos de Extensão (PAPEX) na implantação do software open source BibLivre em sua versão 5.0 em três bibliotecas de escolas da rede estadual de ensino do Ceará.

\section{METODOLOGIA}

O projeto foi submetido no Edital do PAPEX número 001/2019 durante o mês de abril de 2019 e aprovado no mês de junho de 2019. A equipe do projeto é formada por 01 docente e 03 discentes do curso de Bacharelado em Sistemas de Informação. Os discentes foram contemplados com 06 meses de bolsa. As atividades do projeto iniciaram no primeiro dia do mês de agosto se 2019. 
A Figura 02 apresenta o processo que foi utilizado para execução do projeto. Como pode ser identificado na figura 02, o processo tem duas etapas.

A relação de oficinas teóricas se encontra no Quadro 1 e oficinas práticas com peça cadavérica na Quadro 2. Participaram das atividades propostas estudantes vinculadas a cursos de graduação em Educação Física, Medicina, Nutrição, Física Médica, Farmácia, Ciências Biológicas e Biotecnologia da Universidade Federal de Goiás cadastrados no projeto de extensão universitária PJ400-2017, além de estudantes de outras instituições de ensino.

FIGURA 2: FLUXOGRAMA DE EXECUÇÃO.

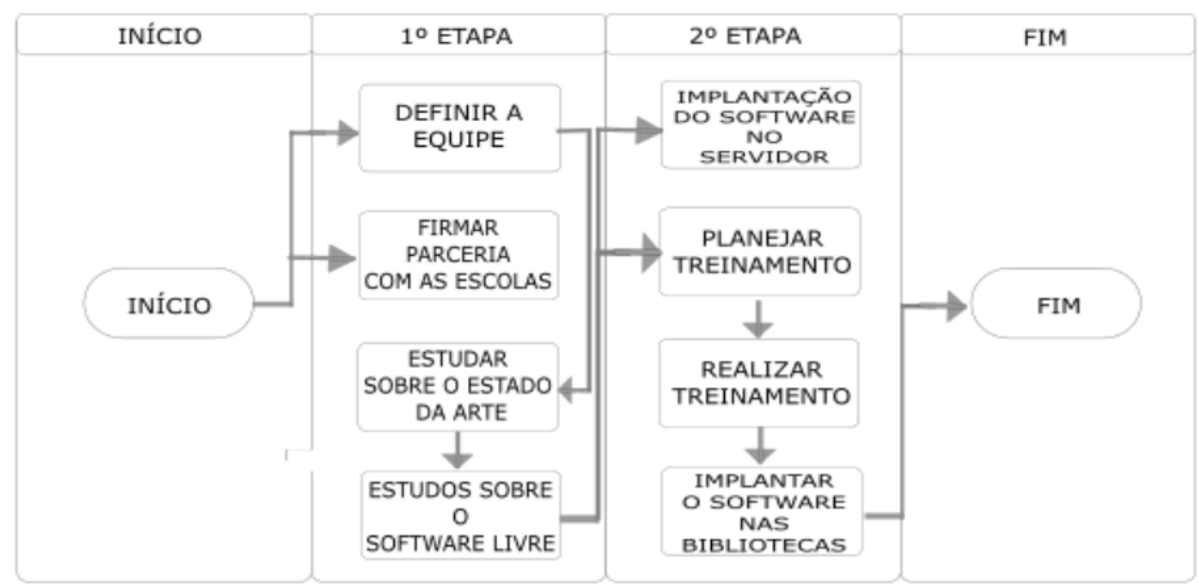

FONTE: OS AUTORES.

Na primeira etapa o docente responsável pelo projeto definiu a equipe, a qual foi composta por o proponente e três discentes do curso de Bacharelado em Sistemas de Informação. Em paralelo, foi mapeado as escolas públicas estaduais da região centro sul do Ceará que não faziam uso de software para gerenciamento do seu acervo, após o mapeamento foi firmado a parceria com três escolas, sendo: 01 Escola Profissional na cidade de Icó-CE, 01 Escola Profissional na cidade de Cedro-CE e 01 Escola Profissional na cidade de Lavras da Mangabeira-CE. nessa etapa também iniciou-se os estudos sobre o estado da arte do tema relacionado e a busca por softwares open sources que tenham como propósito a informatização de bibliotecas.

Para a escolha do software open source que seria utilizado, foi realizado um levantamento bibliográfico acerca dos principais nomes neste nicho, no qual pode-se constatar alguns nomes.

O primeiro deles foi o software Gnuteca, que foi desenvolvido pelo antigo Ministério do Planejamento e Gestão, com o objetivo de automatizar os processos das bibliotecas independentemente do tamanho do acervo ou estrutura da mesma.

O segundo foi o software Koha, "que foi o primeiro sistema de bibliotecas de código aberto e gratuito do mundo. O Koha é um sistema de gerenciamento de 
biblioteca escalável e cheio de recursos" (KOHA, 2019, P. 01). O desenvolvimento do Koha é patrocinado por bibliotecas de vários tipos e tamanhos, voluntários e empresas de suporte em todo o mundo.

O terceiro foi o Biblivre, que é um software livre e gratuito de gerenciamento de bibliotecas que possibilita a catalogação de variados tipos de materiais. Além de ser muito didático, o Biblivre possui funções simples e intuitivas, sua interface é objetiva e funcional, tem comandos simples e práticos, recursos para interagir com usuários e oferece uma ótima ferramenta de pesquisa. Mesmo ele ter sido desenvolvido para o sistema operacional Windows, o Biblivre é multiplataforma (RIBEIRO, 2015, on-line).

Posto em confronto as características dos três softwares acima citados como: funções/recursos, características, aspectos visuais, desempenho, usabilidade, ergonomia, e aplicabilidade na resolução do problema. Escolheu-se, o Biblivre, pois destacou-se de maneira bem superior, em todos os quesitos, como: a possibilidade de acesso de qualquer lugar com internet, ser open source, ser multiplataforma e a possibilidade de gerenciar várias bibliotecas em uma mesma instância instalada.

$\mathrm{Na}$ segunda etapa, após testado e selecionado o software, foi instalado/configurado o BibLivre na versão $5.0 \mathrm{em}$ um servidor, ao mesmo tempo também foi realizado o planejamento do treinamento para os usuários.

O Biblivre está instalado em um servidor remoto localizado no Instituto Federal de Educação, Ciência e Tecnologia do Ceará - campus Cedro, as bibliotecas são os clientes as quais acessam por meio do link: http://200.17.32.103:1234/ Biblivre5/ no navegador. As bibliotecas fazem suas requisições para o servidor, seja para cadastrar um aluno, livro, fazer um empréstimo, buscar algum material e o servidor responde atendendo o pedido. A Figura 03 apresenta a arquitetura utilizada na implantação do software.

Figura 3: ARQUiteTURA CLIENTE-SERVIDOR.

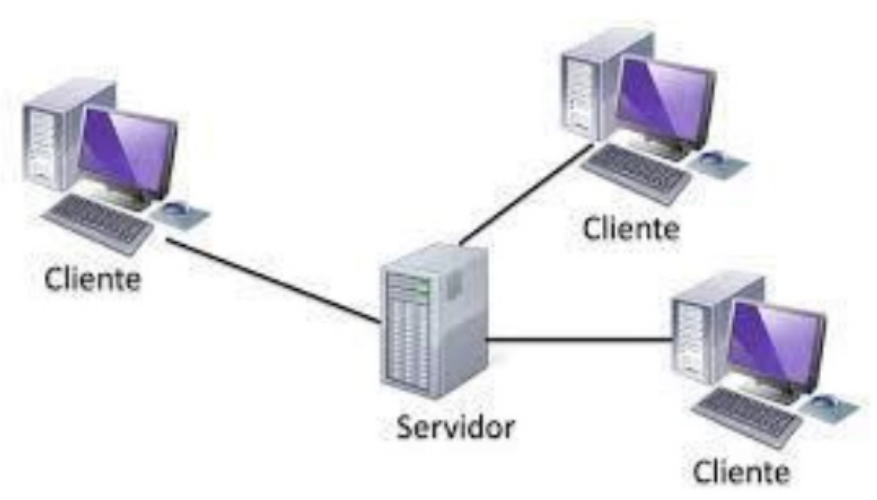

FONTE: ENTREUNOSYCEROS (2013) 
Para executar o processo foi necessário estabelecer algumas metas no início do projeto, como é apresentado no quadro 1. Durante todo o processo, as metas foram acompanhadas e controladas pelo docente.

QUADRO 1: METAS DESENVOLVIDAS.

\begin{tabular}{|c|l|}
\hline MEtA & \multicolumn{1}{c|}{ DESCRIçÃo } \\
\hline 1 & Traçarum perfil das bibliotecas e suas formas de gestão. \\
\hline 2 & Preestabelecer conteúdo e metodologia do treinamento dos usuários. \\
\hline 3 & $\begin{array}{l}\text { Implantar o software no servidor web, organizar as turmas de treinamento e iniciar } \\
\text { o curso de treinamento }\end{array}$ \\
\hline
\end{tabular}

Para alcançar a meta 01, foi necessário realizar uma visita a algumas das escolas de educação básica da rede estadual e conversar com profissionais que atuam nas bibliotecas, com o propósito de entender mais profundamente o funcionamento interno das bibliotecas.

Para alcançar a meta 02, foi organizada e trabalhada a metodologia, referente ao treinamento dos usuários acerca do uso do BibLivre. Nessa etapa foram produzidos manuais e gravado vídeos.

Para alcançar a meta de número 03 foi configurado e efetuada a instalação do software no servidor disponibilizado pelo Instituto Federal de Educação, Ciência e Tecnologia do Ceará - campus Cedro.

Para iniciar a implantação/treinamento em qualquer uma das 03 bibliotecas foi realizado a primeiro momento uma apresentação para os usuários de cada instituição, que aconteceu algumas vezes por videoconferência, outras vezes através de apresentação de forma presencial. Após a apresentação, os discentes configuravam a nova biblioteca no Biblivre e depois junto ao docente executavam o treinamento na escola de forma presencial.

\section{DISCUSSÃO E RESULTADOS}

Essa seção irá apresentar os principais resultados obtidos durante a implantação do Biblivre nas bibliotecas públicas estaduais. Para isso, primeiramente será apresentado no Quadro 2 as funcionalidades básicas do BibLivre.

QUADRO 2: PRINCIPAIS FUNCIONALIDADES DO BIBLIVRE.

FUNCIONALIDADE

Multi Biblioteca
DESCRIÇÃo

Oferece a possibilidade de gerenciamento de várias bibliotecas na mesma plataforma, disponibilizando acessos únicos para cada biblioteca por meio de login e senha individuais para os usuários. 


\begin{tabular}{|c|c|}
\hline Pesquisa & $\begin{array}{l}\text { Após o acesso ter sido realizado com sucesso, o usuário terá à sua } \\
\text { disposição a possibilidade de pesquisar todo o acervo disponível } \\
\text { na biblioteca ao qual o seu login e senha esteja vinculado. } \\
\text { A pesquisa poderá ser realizada por meio de alguns modos, por } \\
\text { exemplo, o modo Bibliográfica, neste modo o usuário poderá } \\
\text { digitar um termo para a pesquisa, escolher o tipo do material, } \\
\text { e em seguida selecionar a opção LISTAR TODOS. } \\
\text { A pesquisa ainda poderá ser feita pelo modo Autoridades, neste } \\
\text { modo a pesquisa será realizada pelo nome dos autores que } \\
\text { estão cadastrados no acervo da biblioteca. } \\
\text { Além disso,épossível realizaruma pesquisa por meio do Vocabulário, } \\
\text { essa função oferece a possibilidade de pesquisar informações acerca } \\
\text { dos termos presentes no acervo desta biblioteca. Ou ainda, pode- } \\
\text { se buscar por meio da pesquisa distribuída, encontrar informações } \\
\text { em acervos de outras bibliotecas que oferecem seus registros para } \\
\text { pesquisa ou catalogação em parceria. }\end{array}$ \\
\hline Circulação & $\begin{array}{l}\text { Nesta opção é oferecido ao usuário a possibilidade de Cadastrar } \\
\text { Usuários, realizar o registro de Empréstimos e Devoluções, que } \\
\text { poderá ser realizado ao selecionar o usuário que está solicitando } \\
\text { o empréstimo, e, após isso selecionar o exemplar que será } \\
\text { disponibilizadoaosolicitante. Na opção Reservas, qualquerusuário } \\
\text { que disponha de login e senha poderá realizar buscas no acervo } \\
\text { da biblioteca que este login e senha esteja vinculado e verificar } \\
\text { se o seu exemplar pretendido está disponível para empréstimo } \\
\text { e efetuar a sua reserva, ou caso o exemplar não esteja disponível } \\
\text { no momento do acesso ele poderá demonstrar o interesse no } \\
\text { exemplar por meio da opção reservar, e ir na biblioteca buscar } \\
\text { o seu exemplar pretendido assim que disponível. Além disso, } \\
\text { a opção Controle de acesso, permite um controle de acesso aos } \\
\text { ambientes físicos da biblioteca, realizando esse gerenciamento } \\
\text { por meio da ferramenta disponibilizada no sistema chamada } \\
\text { Impressão deCarteirinhas. }\end{array}$ \\
\hline Catalogação & $\begin{array}{l}\text { É a área onde o usuário irá realizar o registro de suas obras no } \\
\text { acervo da biblioteca. Este registro poderá ser feito por meio da } \\
\text { opção Bibliográfica, onde será inserido um Novo registro contendo } \\
\text { todas as informações necessárias para a correta identificação } \\
\text { da obra e seus exemplares. Pode ser realizado o cadastro de } \\
\text { uma Autoridade, onde o usuário irá inserir todas as informações } \\
\text { necessárias do autor que poderá ser encontrado por meio da } \\
\text { ferramenta Pesquisar. Ou ainda, pode ser feito a catalogação do } \\
\text { Vocabulário, Importação de registros e ainda a impressão de etiquetas, } \\
\text { esta última que disponibiliza para o usuário uma forma de } \\
\text { identificação de todo o acervo da obra por meio de um registro } \\
\text { e o dispõe para a impressão em diversos modelos. }\end{array}$ \\
\hline Aquisição & $\begin{array}{l}\text { O usuário poderá registrar de várias formas a aquisição das } \\
\text { obras de seu acervo. Por meio de opções como, Fornecedores, } \\
\text { Requisições, Cotações e Pedidos. }\end{array}$ \\
\hline
\end{tabular}




\begin{tabular}{|c|c|}
\hline Administração & $\begin{array}{l}\text { Nessa faixa de opção, é disponibilizado ao usuário várias } \\
\text { ferramentas para a administração da biblioteca a qual ele } \\
\text { está vinculado. Por exemplo, Troca de senhas para os usuário, } \\
\text { gerar Logins e Permissões para acessos externos dos usuários já } \\
\text { cadastrados e vinculados, Tipos de usuário, onde o administrador } \\
\text { poderá selecionar e criar vários tipos de usuários, distribuindo e } \\
\text { restringindo funções que eles poderão utilizar. Cartões de acesso, } \\
\text { Servidores Z39.50, Relatórios, nesta última o administrador poderá } \\
\text { ter acesso a vários relatórios que irão demonstrar o estado atual } \\
\text { do acervo, o estado do usuário e seu histórico. }\end{array}$ \\
\hline Ajuda & $\begin{array}{l}\text { Em caso de alguma dificuldade em usar o sistema Biblivre } \\
\text { o usuário poderá ter acesso a um Manual, nesse ponto ele } \\
\text { poderá ver também perguntas frequentes, que possivelmente } \\
\text { será mesma dúvida. }\end{array}$ \\
\hline
\end{tabular}

Abaixo será apresentado algumas das telas do BibiLivre com dados presentes no servidor.

A Figura 04 apresenta Tela inicial do software onde lista as escolas cadastradas com suas bibliotecas.

A Figura 05 apresenta o formulário de catalogação dos acervos da Biblioteca.

A Figura 06 apresenta o formulário de cadastro de usuário do sistema. Como pode ser visto, o cadastro possui muitos campos (bem completo), mas a maioria dos campos são opcionais, pois o software atende de bibliotecas mais simples a bibliotecas mais complexas.

FIGURA 4: TELA INICIAL DO SOFTWARE.

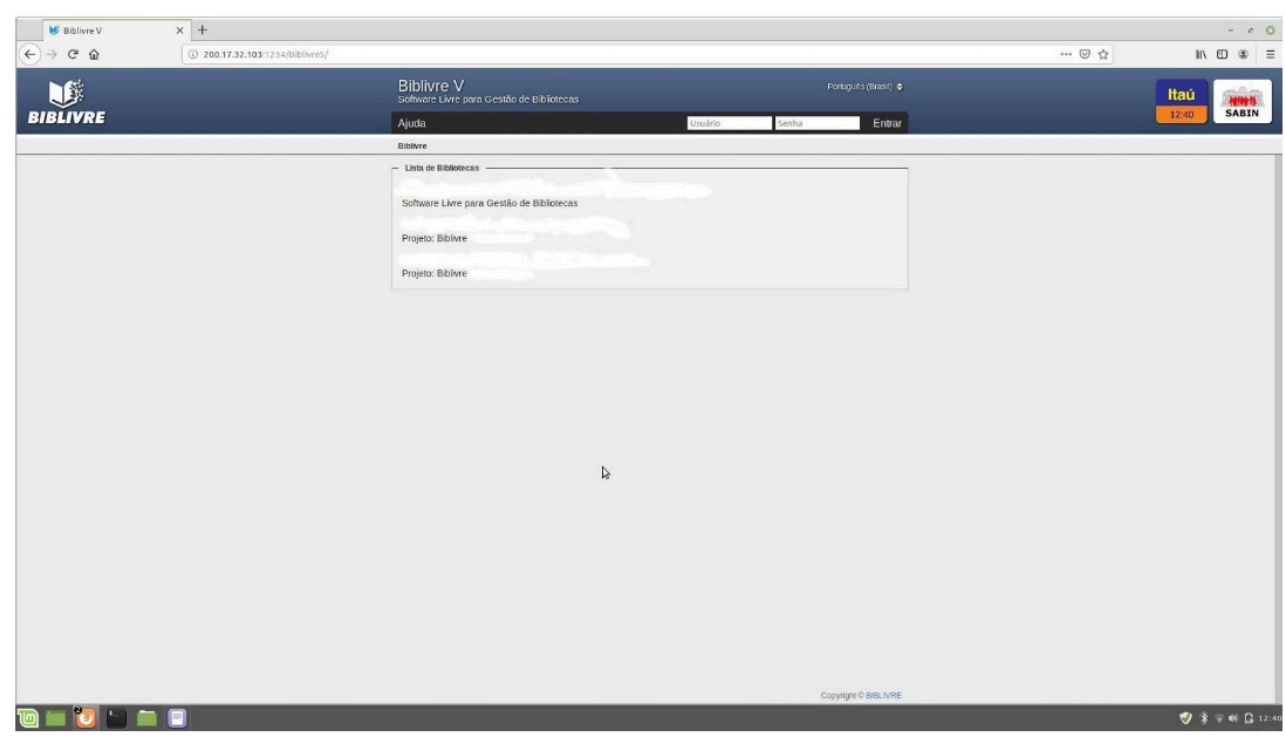

FONTE: OS AUTORES. 
FIGURA 5: FormULÁRIO de CATALOCAÇÃO.

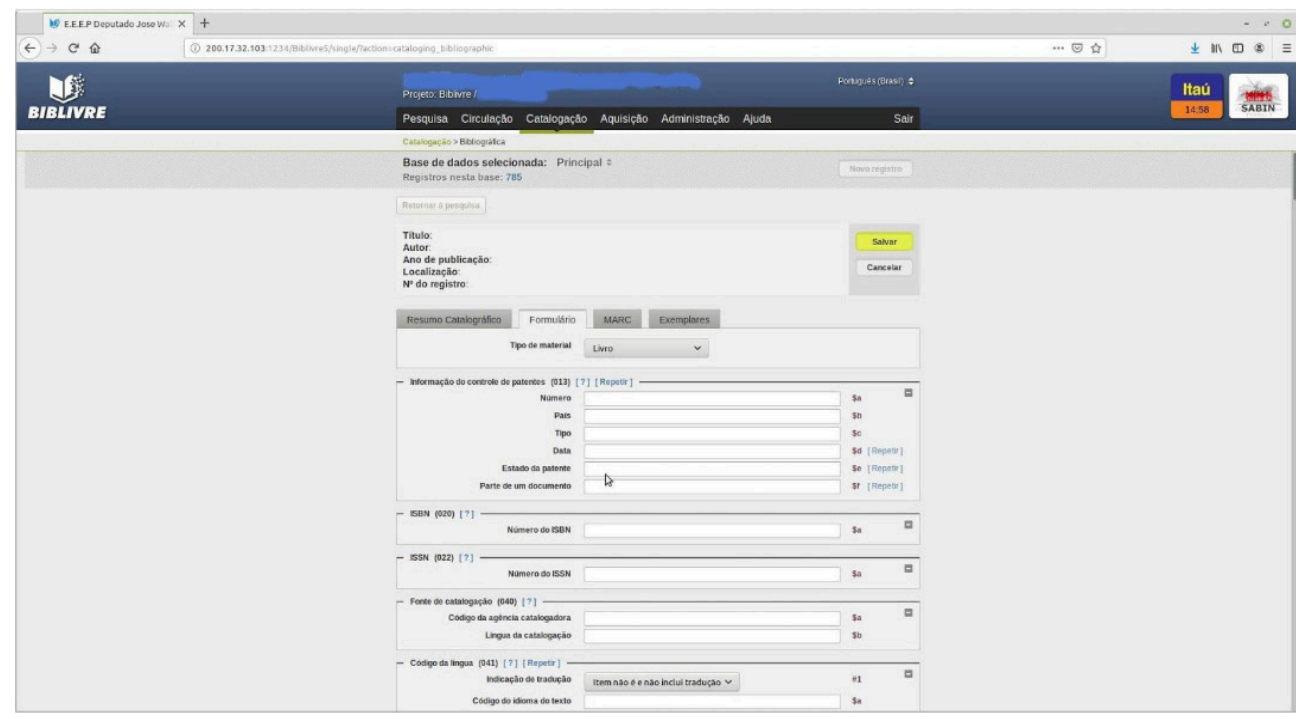

FONTE: OS AUTORES.

FIGURA 6: CADASTRO dE USUÁRIO.

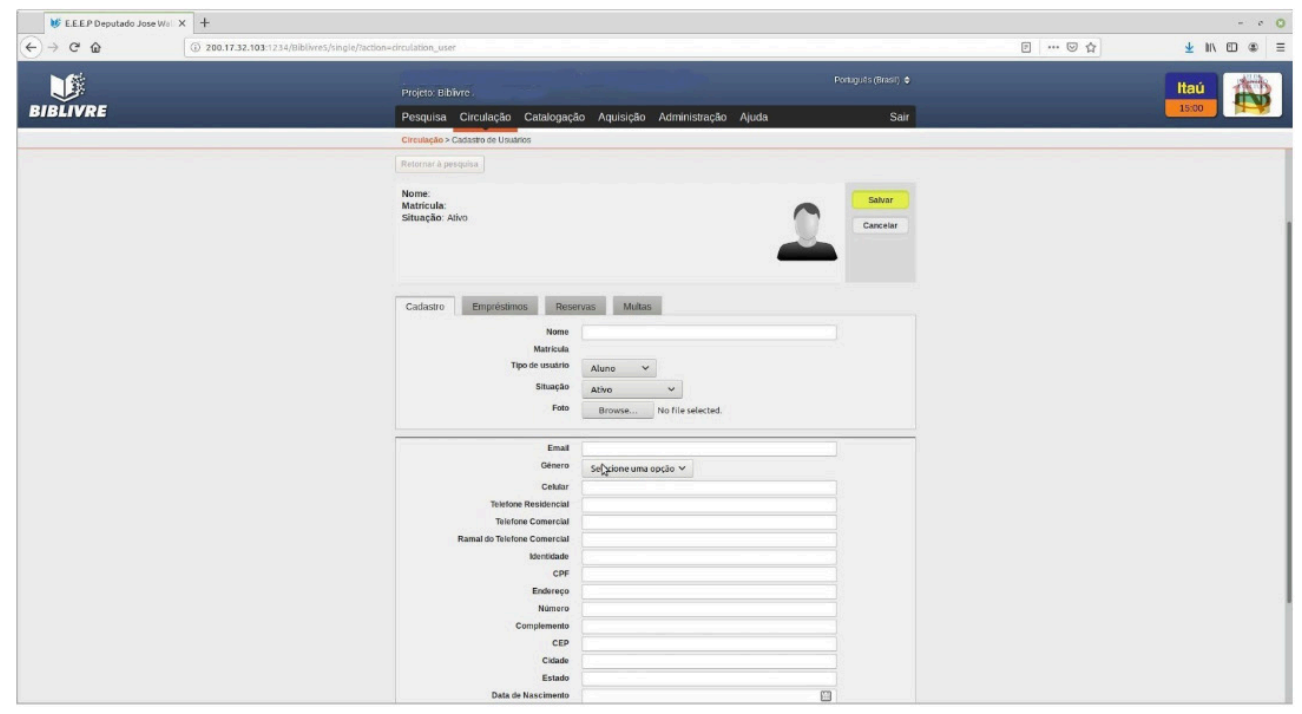

FONTE: OS AUTORES.

Entendida a problemática, foi apresentado de forma presencial aos responsáveis das bibliotecas uma solução integral para todos estes problemas, o software open source Biblivre tendo este primeiro encontro um caráter bem generalista, com o objetivo de demonstrando a estes as principais funcionalidades, como utilizar cada uma delas, dando uma ênfase na parte de catalogação e circulação de exemplar e também expor a parte do aluno, enfatizando que eles terão um acesso 
individual ao software, proporcionado assim uma maior interação entre aluno/ leitor e biblioteca, que após a implantação passaria a ser tanto de forma presencial como de forma online.

Logo mais, também foram realizados encontros de treinamento nas próprias instituições, para explicar o funcionamento de forma detalhada de cada função do software aos usuários e também para observar quais eram suas principais dúvidas e trabalhá-las nos encontros. Observado que alguns usuários tiveram alguns problemas visto o primeiro contato com o programa, também foi desenvolvido pela equipe um mini manual de uso, abordando as principais dúvidas e um passo a passo de como utilizar as principais funções, uma outra forma de auxílio foi o desenvolvimento de vídeos tutoriais haja vista a necessidade.

Com o intuito de fomentar o uso e para também manter um acompanhamento mais rápido, para os casos em que uma visita técnica fosse desnecessária, foi adotado uma estratégia de comunicação por mensagens instantâneas e chamadas de voz. Assim, foi reunido os contatos dos administradores das bibliotecas para a resolução de possíveis dúvidas, pequenos problemas e auxiliar a capacitação dessas pessoas.

Visto a grande necessidade de um entendimento mais completo sobre todo o sistema, e para futuras e possíveis implementações no software pela equipe, visto que o mesmo é de código aberto, foi realizado em cima do banco de dados do Biblivre 5 um processo de engenharia reversa (ER). "A ER constitui na obtenção de informação que caracteriza e especifica o objeto da ação de ER, identificando seus componentes e seu padrão de inter-relacionamento" (DIAS, 2010, p.02). O banco de dados do BibLivre é o PostgreSQL em sua versão 9.1.

Foi desenvolvido um diagrama de entidade relacional (DER) completo de todas as tabelas, um (DER) "É a representação gráfica e principal ferramenta de representação de um banco de dados. Em situações práticas, o diagrama é tido muitas vezes como sinônimo de modelo"(RODRIGUES, 2014, on-line). Para o desenvolvimento do DER foi utilizada a ferramenta MySQL Workbench 8.0.1.

Feito todo o estudo do banco que se consistiu basicamente em 3 etapas:

1. De identificação de entidades, que são as tabelas constituintes do banco de dados;

2. Abstração dos relacionamentos das entidades, ou seja, observar e deduzir quais eram os relacionamentos entre as tabelas;

3. Identificar com base nos relacionamentos obtido a forma do comportamento deste relacionamento que é chamado de cardinalidade.

Realizado este estudo e tendo esses dados em mãos, foi possível produzir o diagrama de identificação de entidades, que vai proporcionar a todos da equipe, um entendimento mais profundo e completo sobre o funcionamento deste. 
A Figura 07 apresenta uma parte do DER desenvolvido pelos integrantes deste projeto. Esse modelo foi importante para entender os dados e os relacionamentos entre esses. A partir desse modelo, conseguiu-se compreender melhor o funcionamento do BibLivre.

O sistema até o momento da escrita deste relato de experiência, contava com:

- 1175 usuários já cadastrados, sendo: alunos, servidores e professores;

- 2826 obras cadastradas, sendo: livros, revistas, artigos;

- 549 empréstimos; e

- 39 empréstimos com atraso;

\section{FIGURA 7: DIAGRAMA ENTIDADE RELACIONAL.}

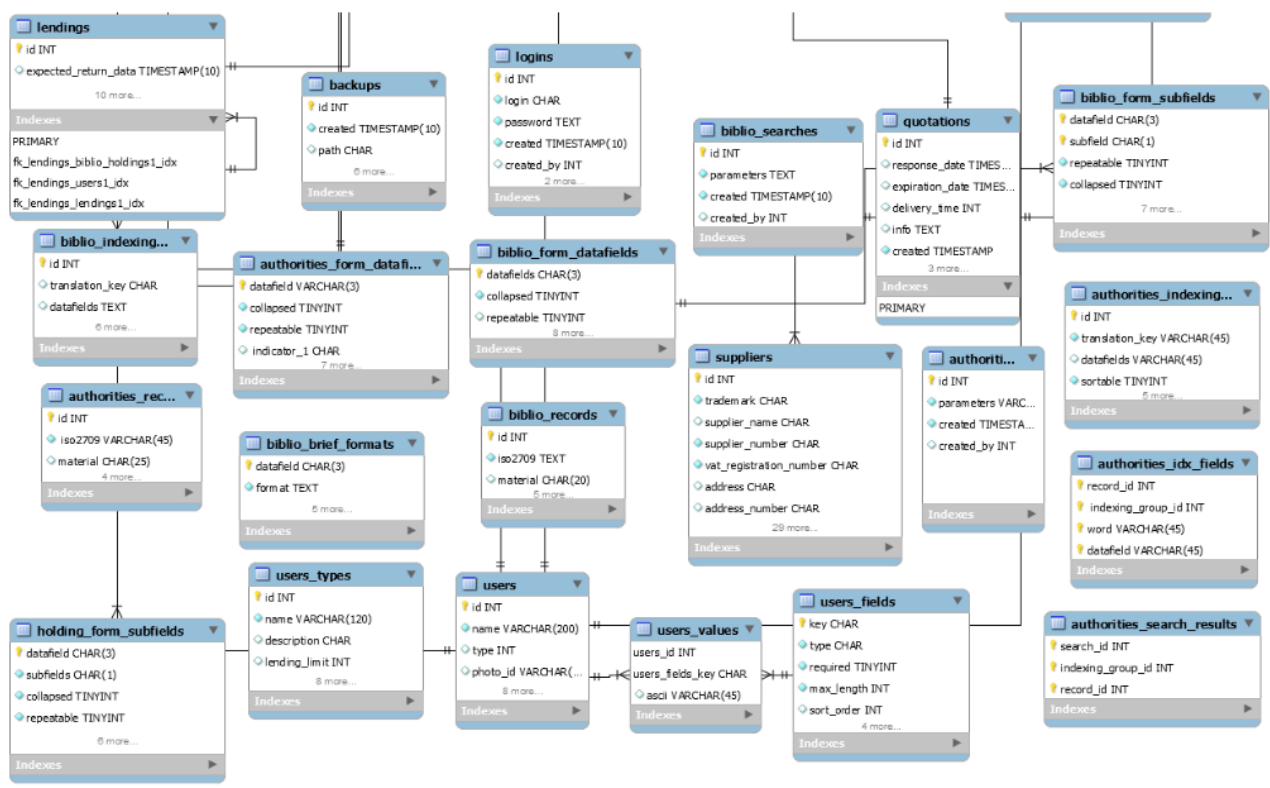

FONTE: OS AUTORES.

Todos estes dados foram gerados automaticamente pelo próprio sistema. Esses números devem aumentar à medida que a circulação acontece nas escolas, como também quando outras escolas aderirem ao sistema de gerenciamento de biblioteca.

A Tabela 1, apresenta dados de quantitativo de professores, de alunos e de funcionários segundo o censo escolar realizado em 2017. Com isso, percebe-se que o projeto de extensão está beneficiando, até o momento, algo em torno de 63 professores, 1183 alunos e 146 funcionários.

TABELA 1: CARACTERIZAÇÃO dOS BENEFICIÁRIOS

\begin{tabular}{|c|c|c|c|c|}
\hline Escola & Cidade & Qtde. Professores & Qtde. Alunos & Qtde. Funcionários \\
\hline Escola A & Icó-CE & 19 & 521 & 50 \\
\hline
\end{tabular}




\begin{tabular}{|c|c|c|c|c|}
\hline Escola B & Cedro-CE & 22 & 348 & 47 \\
\hline Escola C & $\begin{array}{l}\text { Lavras da } \\
\text { Mangabeira- } \\
\text { CE }\end{array}$ & 22 & 314 & 49 \\
\hline
\end{tabular}

FONTE: IDEB (2017).

Espera-se que ao final do projeto, o trabalho tenha sido realizado em mais 04 escolas.

\section{CONSIDERAÇÕES FINAIS}

A implantação do software nas bibliotecas resolveu os problemas internos de gerenciamento destas bibliotecas como: mal gerência, perca de tempo com catalogação manual, isso tudo de forma totalmente gratuita e com bastante eficiência.

Pode-se perceber também que os profissionais que atuam nesses locais conseguiram mais tempo para incentivar os seus alunos a prática da leitura e consequentemente mais eficiência e eficácia na gestão de todo o seu acervo disponível. Além do mais, com a aplicação dos treinamentos, ocorreu uma contribuição profissional significativamente positiva, para aqueles profissionais que atuam nas bibliotecas, proporcionando aos mesmos um novo conhecimento profissional.

Este projeto de extensão não só proporcionou como ainda vai proporcionar um impacto muito positivo na formação dos bolsistas e também do docente, não só de maneira técnica como já foi feito com o DER, com toda parte de configuração do servidor, mais também na formação social dos mesmo, pelo simples fato de ter o contato com novas pessoas dos mais variados níveis de escolaridades, de ver e sentir a realidade de alguma escolas. Também pela conscientização social que um Projeto de Extensão traz que é um meio de retornar para a sociedade, o conhecimento adquirido na universidade pública, através de ações como essa.

Como trabalhos futuros, além de implantar o software em mais 04 bibliotecas, pretende-se desenvolver um módulo para se integrar ao Biblivre, cujo objetivo será acrescentar funções inovadoras como um portal de discussões sobre as obras que estão disponíveis e foram ou serão trabalhadas em algum momento pela turma ou pelo aluno, consequentemente, isso irá oferecer uma interação mais eficiente e simples entre aluno, professor e biblioteca. 


\section{REFERÊNCIAS}

BRASIL. Instituto Nacional de Estudos e Pesquisas Educacionais Anísio Teixeira. Ministério da Educação (Org.). Índice de Desenvolvimento da Educação básica. 2017. Disponível em: http://idebescola.inep.gov.br/ideb/ consulta-publica. Acesso em: 28 set. 2019.

CAMPOS, Augusto. O que é software livre. 2006. Disponível em: http://softwarelivre.ceara.gov.br/index.php/component/content/article/3/318. Acesso em: 09 abr. 2019.

DIAS, Adriano Batista. ENGENHARIA REVERSA: uma porta ainda aberta. Fundação Joaquim Nabuco - Fundaj, Recife, p.0108, out. 2010. Disponível em: https://www.researchgate.net/profile/ Adriano_Dias5/publication/335456099_ENGENHARIA_REVERSA_uma_ porta_ainda_aberta/links/5d6702b4299bf11adf297f04/ENGENHARIA-REVERSA-uma-porta-ainda-aberta.pdf. Acesso em: 28 set. 2019.

ENTREUNOSYCEROS. Selección de arquitecturas y herramientas de programación. 2013. Disponível em: https://entreunosyceros.net/arquitecturas-y-herramientas-programacion/. Acesso em: 29 set. 2019.

FIGUEIREDO, Nice Menezes de. Paradigmas modernos em ciência da informação: em usuários, coleções, referência e informação. São Paulo: Polis, 1999. (Coleção Palavra-Chave, 10);

GNU. 2019. Disponível em: https://www.gnu.org/licenses/licenses.pt-br.html. Acesso em: 09 abr. 2019.

KOHA. 2019. Disponível em: https://koha-community.org/. Acesso em: 09 abr. 2019.

MATTOS, Sérgio Augusto Soares. A REVOLUÇÃO DIGITAL E OS DESAFIOS DA COMUNICAÇÃO. Bahia: Associação Brasileira das Editoras Universitárias, 2013. 208 p. Disponível em: https://www1.ufrb.edu.br/editora/ 
component/phocadownload/category/2-e-books?download=15:a-revolucao-digital-e-os-desafios-da-comunicacao. Acesso em: 08 abr. 2019.

MIRANDA, Ubaldo Santos. Biblivre um novo conceito em automação de bibliotecas. 2016. Disponível em: http://www.uezo.rj.gov.br/biblioteca/static/ Manual_Biblivre_5.0.0.pdf. Acesso em: 09 abr. 2019.

MOURÃO, Rômulo et al. Licenças Open Source e suas implicações sobre o Direito Autoral. Disponível em: http://www.dominiocomum.com/wp-content/ uploads/2016/12/Licen\%C3\%A7as-Open-Source.pdf. Acesso em: 09 abr. 2019.

RIBEIRO, Daniel. Biblivre. 2015. Disponível em: https://www.techtudo.com. br/tudo-sobre/biblivre.html. Acesso em: 29 set. 2019.

RODRIGUES, Joel. Modelo Entidade Relacionamento (MER) e Diagrama Entidade-Relacionamento (DER): Veja neste artigo as definições de Modelo Entidade Relacionamento (MER) e Diagrama Entidade Relacionamento (DER), utilizados na modelagem de bancos de dados.. 2014. Disponível em: https://www.devmedia.com.br/modelo-entidade-relacionamento-mer-e-diagrama-entidade-relacionamento-der/14332\#targetText=Diagrama\%20Entidade\%20Relacionamento,representa\%C3\%A7\%C3\%A3o\%20gr\%C3\%A1fica\%20 e\%20principal\%20ferramenta. Acesso em: 29 set. 2019.

SABINO, Vanessa Cristina. Um estudo sistemático de licenças de software livre. 2011. 116 f. Dissertação (Mestrado) - Curso de Ciência da Computação, Universidade de São Paulo, São Paulo, 2011. Cap. 1. Disponível em: http:// www.teses.usp.br/teses/disponiveis/45/45134/tde-14032012-003454/publico/ MestradoVanessaSabino.pdf. Acesso em: 09 abr. 2019.

SOPHIA. Conheça os impactos da tecnologia no ensino. 2018. Elaborado pela equipe gestora do sistema Sophia. Disponível em: https://www.sophia. com.br/blog/gestao-escolar/conheca-os-impactos-da-tecnologia-no-ensino. Acesso em: 09 abr. 2019.

CORRÊA, Elisa Cristina Delfini; OLIVEIRA, Karina Costa de; BOURSCHEID, Laura da Rosa. BIBLIOTECÁRIO ESCOLAR: UM EDUCADOR? 
DOI: 10.5216/revufg.v19.60585

Acb: Biblioteconomia em Santa Catarina, Santa Catarina, p.107-121, 2002. Disponível em: https://revista.acbsc.org.br/racb/article/view/379/459. Acesso em: 05 out. 2019. 